\title{
EFEITO DA VARIAÇÃO DE TEMPERATURA NA RETRAÇÃO DE ARGAMASSAS DE REPARO COM ADIÇÃO DE MATERIAL PULVERULENTO INERTE
}

\author{
ALMEIDA, Rubyane Brito Rodrigues de \\ Mestranda/Pesquisadora Bolsista \\ UNILA/Fundação Parque Tecnológico Itaipu - \\ Fundação PTI-BR \\ Paraná; Brasil \\ rubyanee.brito@gmail.com \\ SLOVINSKI, Isadora Ghellere \\ Engenheira Civil/Mestranda \\ Universidade Federal da Integração Latino- \\ Americana - UNILA \\ Paraná; Brasil \\ isadoragslovinski@hotmail.com
}

\author{
FARIA, Etore Funchal de \\ Engenheiro Civil Sênior \\ Itaipu Binacional \\ Paraná; Brasil \\ etore@itaipu.gov.br
}

\section{RESUMO}

A obtenção de materiais de reparo eficientes e duráveis para estruturas de concreto depende de vários fatores, mas principalmente da compatibilidade dimensional. A redução de volume, denominada retração, pode provocar tensões de tração e consequentemente fissuração afetando a durabilidade de estruturas reparadas. A adição de material pulverulento inerte em sua composição pode melhorar propriedades como trabalhabilidade e compacidade, porém, é necessário conhecer o comportamento dessas argamassas quando expostas a ambientes encontrados em serviço. Dessa forma, o presente estudo objetiva analisar o comportamento térmico de argamassas cimentícias de reparo para estruturas de concreto. Para tanto foram estudadas substituições parciais do agregado miúdo por material pulverulento de areia natural, nas proporções de 0,12 e $24 \%$ em uma dosagem de argamassa padrão. Os procedimentos de moldagem e ensaio seguiram as especificações da ASTM C596 (2018). Foram realizadas leituras de retração por secagem $\left( \pm 23^{\circ} \mathrm{C}\right)$ até estabilização de massa, quando os corpos de prova foram levados à estufa a $50^{\circ} \mathrm{C}$ e as leituras frequentes prosseguiram. Esse procedimento foi repetido para as temperaturas de 75 e $100^{\circ} \mathrm{C}$. Os resultados obtidos demonstram que houve diferença significativa de retração entre as dosagens a partir dos $50^{\circ} \mathrm{C}$. A dosagem de $24 \%$ apresentou altos valores de retração chegando a $0,6 \mathrm{~mm} / \mathrm{m}$ durante a cura por secagem e a $1,4 \mathrm{~mm} / \mathrm{m}$ aos $100^{\circ} \mathrm{C}$. Já a dosagem de $12 \%$ não apresentou aumento significativo de retração em relação à dosagem de referência, apresentando-se como uma alternativa viável de argamassa de reparo.

Palavras-chave: argamassa, retração, efeito térmico.

\begin{abstract}
Achieving efficient and durable repair materials for concrete structures depends on several factors, but mainly on dimensional compatibility. Volume reduction, called shrinkage, can cause tensile stresses and consequently cracking affecting the maintenance of repaired structures. The addition of inert powdery material in its composition can improve properties such as compactness and workability, however, it is necessary to know the behavior of these mortars when exposed to service environments. Thus, the present study aims to analyze the thermal behavior of repair cement mortars for concrete structures. For this purpose, partial replacements of the fine aggregate by natural sand powdery material were studied, in the proportions of 0,12 and $24 \%$ in a standard mortar dosage. Molding and test procedures followed ASTM C596 (2018) specifications. Drying shrinkage readings were performed until mass stabilization, when the specimens were placed in the stove at $50^{\circ} \mathrm{C}$ and as frequent readings continued. This procedure was repeated for temperatures of 75 and $100^{\circ} \mathrm{C}$. The results show that there was a significant retraction difference between the dosages from $50^{\circ} \mathrm{C}$. The $24 \%$ dosage presented high shrinkage values reaching $0.6 \mathrm{~mm} / \mathrm{m}$ during drying curing and $1.4 \mathrm{~mm} / \mathrm{m}$ at $100^{\circ} \mathrm{C}$. While the dosage of $12 \%$ showed no significant increase in shrinkage compared to the reference dosage, presenting as a viable alternative mortar repair.
\end{abstract}

Keywords: mortar, shrinkage, thermal effect. 


\section{INTRODUÇÃO}

Os materiais de base cimentícia para reparos de estruturas de concreto são muito utilizados devido às suas características de baixo preço, disponibilidade de materiais e compatibilidade com o substrato. Apesar disso, as normas brasileiras ainda não estabeleceram as especificações, características ou propriedades para esses materiais. No entanto, fatores como a compatibilidade dimensional entre o material de reparo e a estrutura são de extrema importância na obtenção de um reparo eficiente e durável.

Yildirim, Sahmaran e Anil (2018) apresentaram um modelo holístico multivariado das propriedades dos materiais de reparo, em que consideraram a compatibilidade dimensional, compreendendo a fluência, módulo de elasticidade, expansão térmica, capacidade de deformação e retração, uma das mais importantes.

A retração pode ser definida basicamente como a redução de volume do material que ocorre pelo consumo de água de mistura (retração plástica) no concreto recém-moldado, ou devido à perda de umidade do concreto endurecido para $\mathrm{o}$ ambiente (retração por secagem) (BANTHIA e GUPTA, 2009; NEVILLE, 2015).

Apesar de ser considerada uma propriedade intrínseca do concreto, que ocorre desde a mistura dos materiais e se prolonga durante toda a vida útil da estrutura, a retração está diretamente relacionada à qualidade e durabilidade das construções. As tensões causadas pela retração devido às restrições existentes nas estruturas, podem ocasionar a fissuração do material facilitando a entrada de agentes agressivos. Em materiais de reparo, esse fenômeno tem papel fundamental na viabilidade de aplicação e na compatibilidade entre reparo e estrutura, visto que uma das maiores dificuldades encontradas em reparos de estruturas de concreto é o fato de a retração do material de reparo ser muito maior que a da estrutura sobre a qual é aplicado (QIN et al., 2019).

De acordo com Mehta e Monteiro (2008), a água pode existir de diversas formas dentro da pasta de cimento hidratada e pode ser classificada de acordo com a facilidade com que pode ser removida, sendo essencial no entendimento das alterações volumétricas do material. Ao contrário da retração autógena, na retração por secagem a água perdida não está relacionada às reações de hidratação do cimento e ocorre com a redução de volume do material pela retirada de água quimicamente adsorvida (aquela não mais disponível) por evaporação (FARIA, 2012) e pode ser minimizada ou evitada com procedimentos físicos, adensamento e cura adequados (HOLT, 2001).

Assim, dentre os principais fatores que afetam a retração por secagem, as condições ambientais como temperatura e umidade relativa do ar são extremamente importantes, devendo ser consideradas dentro das leis de comportamento do material ao longo do tempo (HOLT, 2001; PONS E TORRENTI, 2014).

A adição de finos em concretos e argamassas pode melhorar a trabalhabilidade e a microestrutura do material pela densificação de empacotamento das partículas até a dosagem ótima (DUVAL e KADRI, 1998; KADRI et al., 2010). As adições que são consideradas inertes são as quimicamente não reativas e o efeito da utilização desses materiais depende da forma e finura de sua partícula. Os materiais pulverulentos (com dimensão $<0,075 \mathrm{~mm}$ ) têm sido empregados para melhorar várias propriedades e reduzir a retração em concretos (BAUER, NORONHA e BAUER, 2014).

Nesse sentido, o presente trabalho tem como objetivo analisar a influência da variação da temperatura na retração de argamassas de reparo com adição de material pulverulento inerte através de ensaios de retração por secagem.

\section{PROGRAMA EXPERIMENTAL}

O programa experimental foi divido em duas etapas principais: caracterização dos materiais e análises das retrações por secagem. Foram estudadas duas argamassas com substituição da areia natural por material pulverulento nos teores de $12 \%$ e $24 \%$, além da referência, intituladas A12, A24 e A0, respectivamente. As análises foram realizadas com os corpos de prova submetidos a $23^{\circ} \mathrm{C}$, temperatura recomendada para o ensaio, e a $50^{\circ} \mathrm{C}, 75^{\circ} \mathrm{C}$ e $100^{\circ} \mathrm{C}$, com o uso de estufa, para identificar perdas de água e retrações adicionais. $\mathrm{O}$ estudo foi desenvolvido nos Laboratórios de Tecnologia do Concreto de Itaipu e de Desempenho, Estruturas e Materiais da Universidade Federal da Integração LatinoAmericana - UNILA. 


\subsection{Materiais}

Os materiais utilizados no presente estudo foram cimento Portland CP IV-32 RS (Tabela 1), caracterizado conforme a NBR 7215 (ABNT, 2014), areia natural do rio Paraná (AN), material pulverulento (MP) de areia natural do rio Paraná $(<75 \mu \mathrm{m})$ e água potável proveniente da rede de abastecimento interna de Itaipu.

Tabela 1 - Propriedades do Cimento Portland CP IV-32 RS

\begin{tabular}{|c|c|c|c|c|}
\hline \multicolumn{3}{|c|}{ Propriedades } & Resultado Fabricante & Resultado ensaios \\
\hline \multirow{4}{*}{ Químicas } & \multicolumn{2}{|c|}{ Perda ao Fogo $(\%)$} & 3,28 & - \\
\hline & \multicolumn{2}{|c|}{ Óxido de Magnésio - MgO (\%) } & 4,90 & - \\
\hline & \multicolumn{2}{|c|}{ Trióxido de enxofre - SO3 (\%) } & 2,33 & - \\
\hline & \multicolumn{2}{|c|}{ Resíduo insolúvel (\%) } & 27,66 & - \\
\hline \multirow{12}{*}{ Físicas e mecânicas } & \multicolumn{2}{|c|}{ Massa específica $\left(\mathrm{g} / \mathrm{cm}^{3}\right)$} & 2,87 & - \\
\hline & \multicolumn{2}{|c|}{ Finura \#200 (\%) } & 0,38 & - \\
\hline & \multicolumn{2}{|l|}{ Finura \#325 (\%) } & 1,83 & - \\
\hline & \multicolumn{2}{|l|}{ Blaine $\left(\mathrm{cm}^{2} / \mathrm{g}\right)$} & 4626,00 & - \\
\hline & \multicolumn{2}{|c|}{ Água de consistência (\%) } & 29,96 & - \\
\hline & \multicolumn{2}{|c|}{ Início tempo de pega (min) } & 263,25 & - \\
\hline & \multicolumn{2}{|c|}{ Fim tempo de pega (min) } & 331,50 & - \\
\hline & \multicolumn{2}{|c|}{ Expansibilidade a quente (mm) } & 0,00 & - \\
\hline & \multirow{4}{*}{$\begin{array}{l}\text { Resistência à } \\
\text { compressão (MPa) }\end{array}$} & 1 dia & 13,11 & 14,85 \\
\hline & & 3 dias & 24,50 & 30,88 \\
\hline & & 7 dias & 30,21 & 39,51 \\
\hline & & 28 dias & 43,25 & 59,34 \\
\hline
\end{tabular}

Fonte: Fabricante (2016) adaptado pela autora

A areia natural do Rio Paraná foi caracterizada por ensaio de granulometria preconizado pela norma C136 (ASTM, 2014), massa específica e absorção de água pela norma C128 (ASTM, 2015), resultando em 2,53 g/cm ${ }^{3}$ e $0,37 \%$, respectivamente. $\mathrm{O}$ material pulverulento foi obtido a partir da moagem da areia natural em moinho de bolas de revestimento cerâmico para evitar contaminação. Foi peneirado em peneira $\# 200$ e caracterizado por ensaio de granulometria a laser em analisador de partículas Cilas 1190 por via úmida, assim como o cimento. A Figura 1 apresenta as curvas granulométricas do cimento Portland (CP), do material pulverulento (MP) e da areia natural (AN).

A areia natural apresenta granulometria dentro dos limites estabelecidos como adequados pela norma C144 (ASTM, 2018), diâmetro máximo característico de 2,38 e módulo de finura de 2,32.

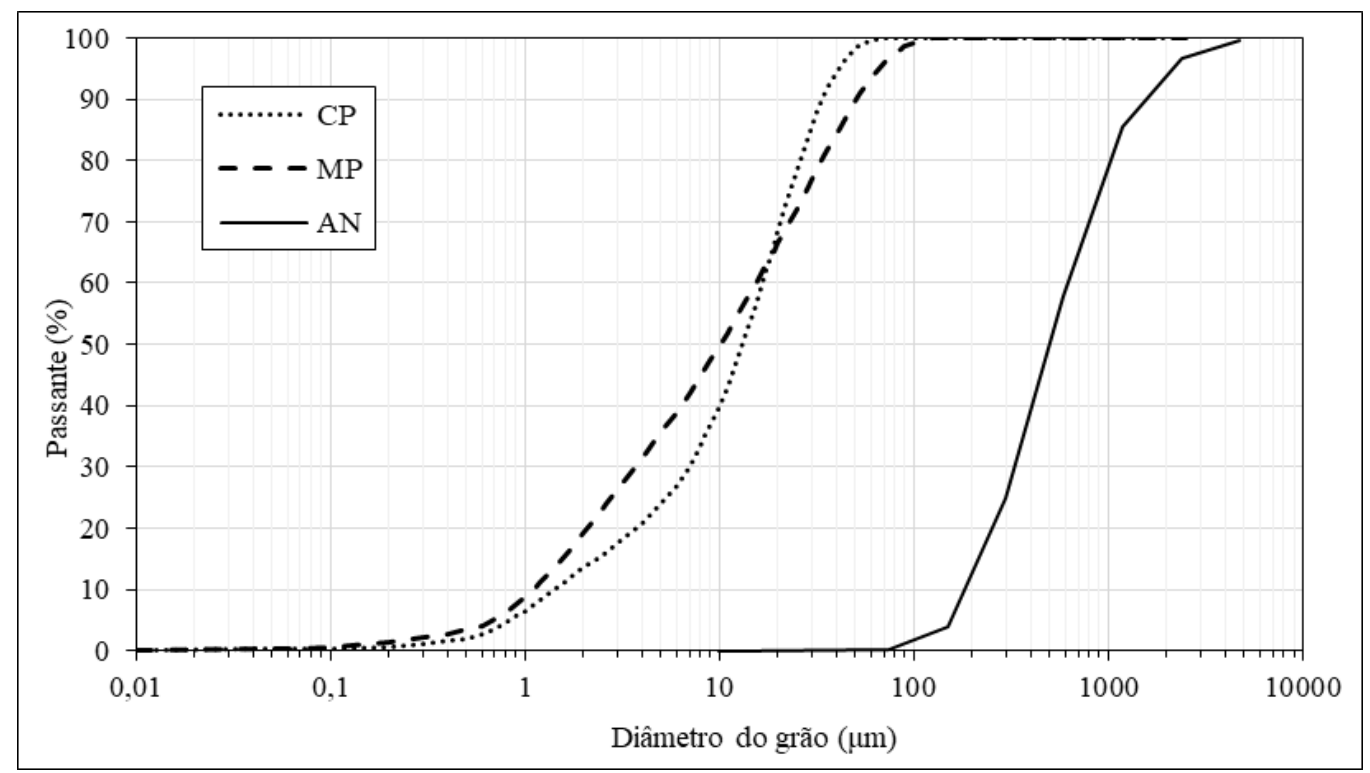

Figura 1: Curvas granulométricas dos materiais utilizados 


\subsection{Dosagens}

As dosagens das argamassas estudadas foram $\mathrm{A} 0$, com $100 \%$ de areia natural (sem material pulverulento); A12, com $88 \%$ de areia natural e $12 \%$ de material pulverulento; e A24, com $76 \%$ de areia natural e $24 \%$ de material pulverulento. Com foco na influência do material pulverulento na retração das argamassas, utilizou-se um traço padrão de argamassa de cimento e areia $(1: 3: 0,53)$, sem adições ou aditivos. A relação água/cimento foi definida em função da trabalhabilidade da argamassa com maior teor de material pulverulento. $\mathrm{O}$ resumo das nomenclaturas adotadas para as argamassas estudadas estão apresentadas na Tabela 2, considerando teor de material pulverulento e temperatura de exposição das amostras.

Tabela 2 - Nomenclaturas das argamassas estudadas

\begin{tabular}{c|c|c|c|c}
\hline \multirow{2}{*}{$\begin{array}{c}\text { Teor de material } \\
\text { pulverulento }\end{array}$} & \multicolumn{4}{|c}{ Temperaturas de exposição } \\
\cline { 2 - 5 } & $23^{\circ} \mathrm{C}$ & $50^{\circ} \mathrm{C}$ & $75^{\circ} \mathrm{C}$ & $100^{\circ} \mathrm{C}$ \\
\hline $0 \%$ & $\mathrm{~A} 0$ & $\mathrm{~A} 0 / 50$ & $\mathrm{~A} 0 / 75$ & $\mathrm{~A} 0 / 100$ \\
\hline $12 \%$ & $\mathrm{~A} 12$ & $\mathrm{~A} 12 / 50$ & $\mathrm{~A} 12 / 75$ & $\mathrm{~A} 12 / 100$ \\
\hline $24 \%$ & $\mathrm{~A} 24$ & $\mathrm{~A} 24 / 50$ & $\mathrm{~A} 24 / 75$ & $\mathrm{~A} 24 / 100$ \\
\hline
\end{tabular}

\subsection{Mistura, Moldagem e Cura}

As argamassas foram produzidas em um misturador mecânico. Toda a água de mistura foi colocada na cuba e o cimento foi sendo adicionado com o misturador em velocidade baixa por 30s. Com o misturador ainda ligado, a areia foi adicionada de modo constante durante 30 s e o misturador foi colocado em velocidade alta por mais 30 s. Imediatamente após a mistura, o misturador foi desligado, retirou-se a argamassa aderida das paredes da cuba e a argamassa permaneceu em repouso, coberta por um pano úmido, por $1 \mathrm{~min}$. e 15s. Após esse intervalo, a argamassa foi misturada em velocidade alta por mais 1 min.

Após o término da mistura foram realizados ensaios de consistência das argamassas de acordo com a NBR 13276 (ABNT, 2016). Os resultados médios obtidos foram de 320, 286 e $269 \mathrm{~mm}$ para as argamassas A0, A12 e A24, respectivamente.

Foram moldados 6 corpos de prova para cada dosagem (A0, A12 e A24), totalizando $18 \mathrm{cps}$. A moldagem seguiu as especificações da norma C157 (ASTM, 2017) e a distância interna (G) entre os parafusos foi medida antes do preenchimento dos moldes por ser esta a referência para o cálculo do valor da retração. A cura ao ar foi realizada por 48 horas em ambiente com temperatura controlada $\left(23 \pm 2^{\circ} \mathrm{C}\right)$ e após desmoldagem procedeu-se com a cura por imersão em solução saturada de hidróxido de cálcio a $23 \pm 2^{\circ} \mathrm{C}$ por 24 horas.

\subsection{Determinações da Retração por Secagem e por Variação Térmica}

Após a cura, os corpos de prova de argamassa foram acondicionados em bancada sobre dois membros não absortivos com área de rolamento de aproximadamente $5 \mathrm{~mm}$ e espaçados $25 \mathrm{~mm}$ entre si para que houvesse adequada circulação de ar em todas as suas faces (Figura 2).

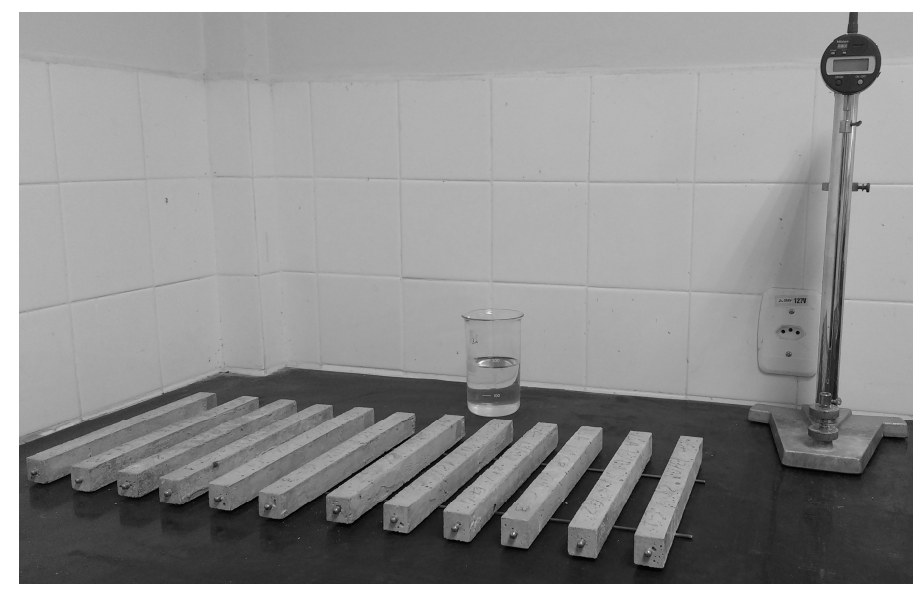

Figura 2: Acondicionamento dos corpos de prova e aparato medidor de retração 
Os corpos de prova foram expostos à secagem sendo realizadas leituras frequentes de retração e massa. Foram mantidos em temperatura ambiente $\left(23 \pm 2^{\circ} \mathrm{C}\right)$ e umidade relativa de $50 \pm 5 \%$ com medições diárias por termohigrômetro. As leituras foram realizadas anotando-se o maior valor verificado em leve rotação do corpo de prova no equipamento medidor, segundo especificações da norma C490 (ASTM, 2017). Após a estabilização de massa em temperatura ambiente em torno dos 20 dias de idade, os corpos de prova foram colocados em estufa a $50^{\circ} \mathrm{C}$ e as leituras de retração e massa foram realizadas também até suas estabilizações em três leituras consecutivas. $\mathrm{O}$ ambiente de ensaio foi mantido em temperatura controlada $\left(23 \pm 2^{\circ} \mathrm{C}\right)$ e umidade relativa de $50 \pm 5 \%$, o procedimento foi repetido para as temperaturas na estufa de $50^{\circ} \mathrm{C}, 75^{\circ} \mathrm{C}$ e $100^{\circ} \mathrm{C}$.

Ressalta-se que as leituras de retração e variação de massa da argamassa A24 foram realizadas em momento distinto das argamassas A0 a A12, porém seguindo-se as mesmas condições do ambiente e as especificações de norma.

\section{RESULTADOS}

O gráfico da Figura 3 apresenta os resultados médios de retração por secagem e por variação térmica das argamassas estudadas.

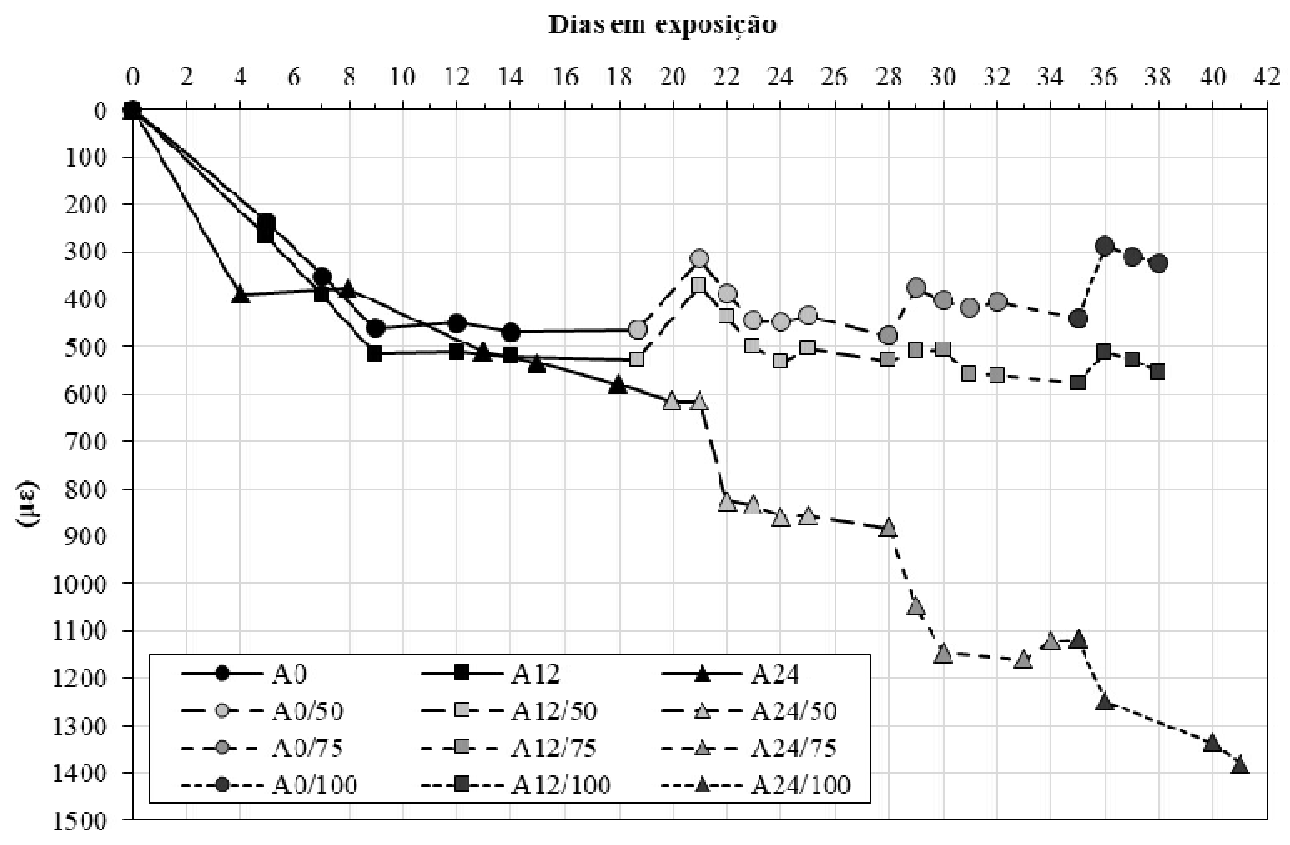

Figura 3: Variação volumétrica das argamassas

Observa-se da Figura 3 que os comportamentos das argamassas A0 e A12 foram similares, enquanto da argamassa A24 foi discrepante, principalmente a partir da temperatura de $50^{\circ} \mathrm{C}$. As retrações máximas das argamassas A0, A12 e A24, durante a secagem a $23 \pm 2^{\circ} \mathrm{C}$ foram, respectivamente, iguais a $0,47 \mathrm{~mm} / \mathrm{m}, 0,53 \mathrm{~mm} / \mathrm{m} \mathrm{e} 0,61 \mathrm{~mm} / \mathrm{m}$. A $50^{\circ} \mathrm{C}$, a $75^{\circ} \mathrm{C}$ e a $100^{\circ} \mathrm{C}$, as argamassas A24/50, A24/75 e A24/100 atingiram valores iguais a $0,89 \mathrm{~mm} / \mathrm{m}, 1,16 \mathrm{~mm} / \mathrm{m}$ e $1,40 \mathrm{~mm} / \mathrm{m}$ de retrações máximas, respectivamente, enquanto as argamassas A0 e A12 não apresentaram variações significativas. A diferença máxima de retração entre as argamassas A0/100 e A24/100 foi de 68\%.

Pelo teste estatístico de análise de variância ANOVA, houve diferença significativa de retração entre dosagens nas temperaturas de 50,75 e $100^{\circ} \mathrm{C}$. A análise estatística está apresentada na Tabela 3. 
Tabela 3 - Análise estatística ANOVA da variação volumétrica das argamassas

\begin{tabular}{|c|c|c|c|c|c|c|c|}
\hline $\begin{array}{l}\text { Temperatura } \\
\text { de Exposição }\end{array}$ & $\begin{array}{l}\text { Causas da } \\
\text { variação }\end{array}$ & $\begin{array}{c}\text { SQ (soma } \\
\text { dos } \\
\text { quadrados) }\end{array}$ & $\begin{array}{l}\text { Graus de } \\
\text { Liberdade }\end{array}$ & $\begin{array}{l}\text { Quadrado } \\
\text { Médio }\end{array}$ & $\begin{array}{c}\text { F calculado } \\
\text { (teste de } \\
\text { Fisher) }\end{array}$ & $\begin{array}{c}\text { P (nível de } \\
\text { significância) }\end{array}$ & Significância \\
\hline \multirow{3}{*}{$23^{\circ} \mathrm{C}$} & Entre grupos & 23357,1 & 2 & 11678,6 & 0,3081 & 0,7386 & $\mathrm{NS}$ \\
\hline & Resíduo & 682213 & 18 & 37900,7 & & & \\
\hline & Total & 705570 & 20 & 0,7338 & & & \\
\hline \multirow{3}{*}{$50^{\circ} \mathrm{C}$} & Entre grupos & 538290 & 2 & 269145 & 47,53 & $3,22 \mathrm{E}-07$ & $\mathrm{~S}$ \\
\hline & Resíduo & 84939,1 & 15 & 5662,61 & & & \\
\hline & Total & 623229 & 17 & $3,00 \mathrm{E}-05$ & & & \\
\hline \multirow{3}{*}{$75^{\circ} \mathrm{C}$} & Entre grupos & $1,42 \mathrm{E}+06$ & 2 & 711791 & 609,3 & $8,60 \mathrm{E}-13$ & $\mathrm{~S}$ \\
\hline & Resíduo & 14017,8 & 12 & 1168,15 & & & \\
\hline & Total & $1,44 \mathrm{E}+06$ & 14 & $1,00 \mathrm{E}-05$ & & & \\
\hline \multirow{3}{*}{$100^{\circ} \mathrm{C}$} & Entre grupos & $1,71 \mathrm{E}+06$ & 2 & 853333 & 475,5 & $2,46 \mathrm{E}-07$ & $\mathrm{~S}$ \\
\hline & Resíduo & 10766,9 & 6 & 1794,48 & & & \\
\hline & Total & $1,72 \mathrm{E}+06$ & 8 & 0,00353 & & & \\
\hline
\end{tabular}

A adição de material pulverulento pode ser considerada aproximadamente $86,4 \%, 99,0 \%$ e 99,4\% responsável pela variação da retração nas temperaturas de 50,75 e $100^{\circ} \mathrm{C}$, respectivamente. A análise ANOVA apontou que existe diferença significativa entre as temperaturas, mas não especifica quais das dosagens diferem. Já o teste de Tukey aponta as diferenças significativas de retração entre as dosagens (valores abaixo de 0,05 ) em cada temperatura de exposição, de acordo com a Tabela 4.

Tabela 4 - Teste de Tukey (células destacadas apresentam diferença significativa)

\begin{tabular}{|c|c|c|c|c|}
\hline Temperatura de exposição & Argamassas & A0 & A12 & A24 \\
\hline \multirow{3}{*}{$23^{\circ} \mathrm{C}$} & $\mathrm{A} 0$ & & 0,9107 & 0,7169 \\
\hline & A12 & 0,5843 & & 0,9271 \\
\hline & A24 & 1,11 & 0,5254 & \\
\hline \multirow{3}{*}{$50^{\circ} \mathrm{C}$} & A0 & & 0,3637 & $5,164 \mathrm{E}-07$ \\
\hline & A12 & 1,986 & & $4,20 \mathrm{E}-06$ \\
\hline & A24 & $1,28 \mathrm{E}+01$ & $1,08 \mathrm{E}+01$ & \\
\hline \multirow{3}{*}{$75^{\circ} \mathrm{C}$} & $\mathrm{A} 0$ & & 0,0001219 & $9,94 \mathrm{E}-13$ \\
\hline & A12 & 8,797 & & $7,36 \mathrm{E}-12$ \\
\hline & A24 & 46,47 & 37,67 & \\
\hline \multirow{3}{*}{$100^{\circ} \mathrm{C}$} & $\mathrm{A} 0$ & & 0,001554 & 4,19E-07 \\
\hline & A12 & 9,171 & & $1,23 \mathrm{E}-06$ \\
\hline & A24 & 41,51 & 32,34 & \\
\hline
\end{tabular}

O teste apontou diferença significativa de retração entre as argamassas A0 e A24, A12 e A24 aos $50^{\circ} \mathrm{C}$ e entre as argamassas A0 e A12, A0 e A24 e A12 e A24 nas temperaturas de 75 e $100^{\circ} \mathrm{C}$. Os resultados demonstram que a argamassa A24 apresentou diferença significativa de retração em relação às argamassas A0 e A12 nas temperaturas de 50,75 e $100^{\circ} \mathrm{C}$.

O gráfico da Figura 4 apresenta os resultados médios de variação de massa das argamassas estudadas. 


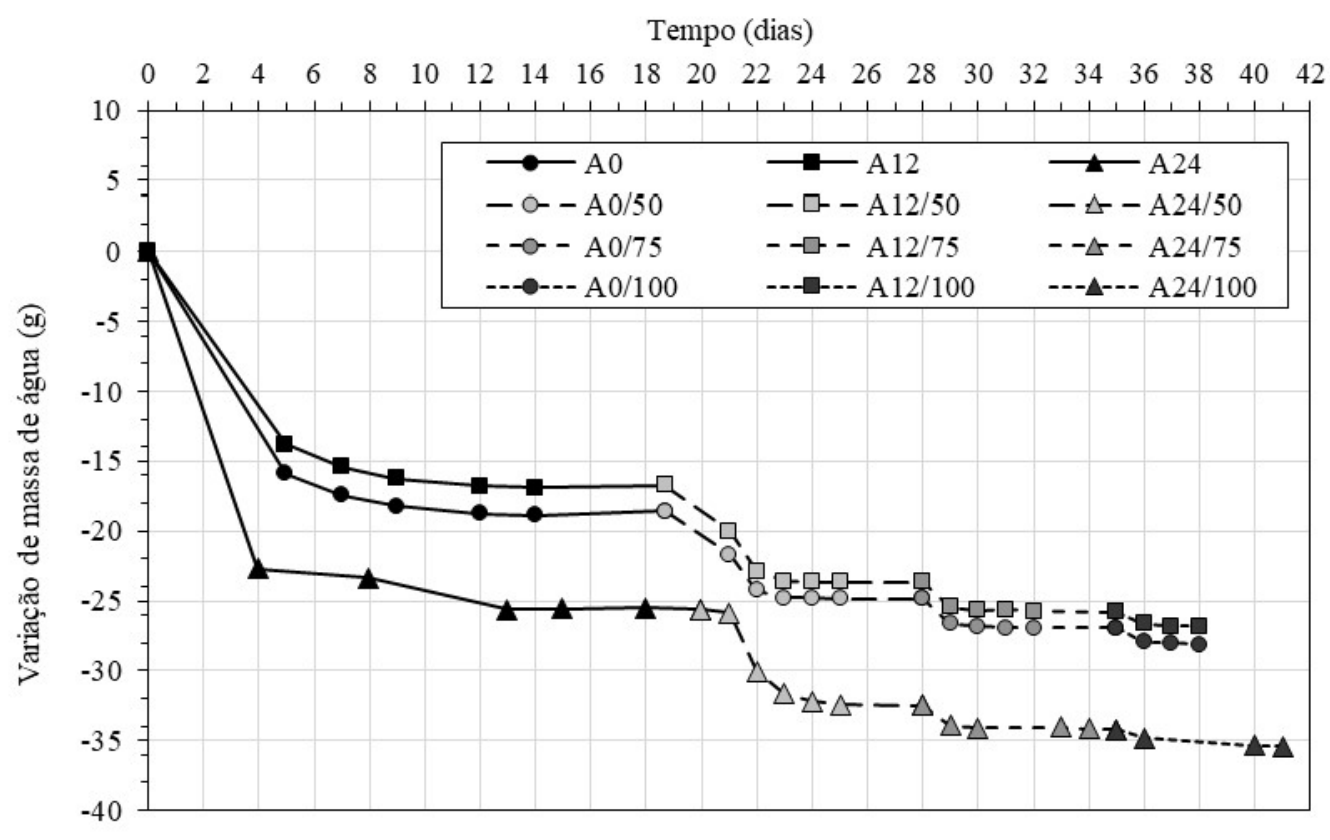

Figura 4: Variação da massa de água das argamassas

A variação de massa apresentada na Figura 3 demonstra resultados próximos entre as argamassas A0 e A12, com uma diferença máxima de $2,15 \mathrm{~g}$ ou $13,5 \%$. Em relação à argamassa A24, esta apresentou variação máxima de massa aos $100^{\circ} \mathrm{C}$ de $35,43 \mathrm{~g}$, o que representa $24,3 \%$ a mais que a argamassa de referência $\mathrm{A} 0$. A partir dos $75^{\circ} \mathrm{C}$ de exposição, os valores de retração dentro da mesma dosagem não apresentaram grandes variações.

\section{CONSIDERAÇÕES FINAIS E CONCLUSÕES}

Os resultados obtidos demonstram a viabilidade da argamassa de reparo com $12 \%$ de substituição do agregado miúdo por material pulverulento de areia natural em relação à retração por secagem, por não apresentar variação expressiva dessa propriedade em relação à argamassa de referência, mesmo com a variação de temperatura. Por outro lado, a argamassa A24 apresenta altos valores de retração e grande variação dessa propriedade em temperaturas acima de $50^{\circ} \mathrm{C}$, tornando-se inadequada para aplicação em campo exposta a estas condições. A variação de retração a partir dos $75^{\circ} \mathrm{C}$ não foi significativa, sendo porcentagem de adição de material pulverulento portanto, a variável mais relevante no presente estudo. Ressalta-se, porém, a importância da investigação de propriedades adicionais das argamassas para análises mais aprofundadas de compatibilidade com o substrato.

\section{AGRADECIMENTOS}

O presente trabalho foi realizado com o apoio financeiro da Fundação Parque Tecnológico Itaipu - Fundação PTI-BR. Agradecemos à Fundação Parque Tecnológico Itaipu - PTI-BR, à Universidade Federal da Integração Latino Americana - UNILA e à Itaipu Binacional.

\section{REFERÊNCIAS}

AMERICAN SOCIETY OF TESTING MATERIALS. C128: Standard Test Method for Relative Density (Specific Gravity) and Absorption of Fine Aggregate. West Conshohocken: ASTM, 2015. 6 p.

AMERICAN SOCIETY OF TESTING MATERIALS. C136: Standard Test Method for Sieve Analysis of Fine and Coarse Aggregates. West Conshohocken: ASTM, 2014. 5 p.

AMERICAN SOCIETY OF TESTING MATERIALS. C144: Standard Specification for Aggregate for Masonry Mortar. West Conshohocken: ASTM, 2018. 3 p. 
AMERICAN SOCIETY OF TESTING MATERIALS. C157: Standard Test Method for Length Change of Hardened Hydraulic-Cement Mortar and Concrete. West Conshohocken: ASTM, 2017. 8 p.

AMERICAN SOCIETY OF TESTING MATERIALS. C490: Standard Practice for Use of Apparatus for the Determination of Lenght Change of Hardened Cement Paste, Mortar and Concrete. West Conshohocken: ASTM, 2017. $5 \mathrm{p}$.

AMERICAN SOCIETY OF TESTING MATERIALS. C596: Standard Test Method for Drying Shrinkage of Mortar Containing Hydraulic Cement. West Conshohocken: ASTM, 2018. 4 p.

ASSOCIAÇÃO BRASILEIRA DE NORMAS TÉCNICAS. NBR 7215: Cimento Portland - Determinação da resistência à compressão de corpos de prova cilíndricos. Rio de Janeiro, 2014.

ASSOCIAÇÃO BRASILEIRA DE NORMAS TÉCNICAS. NBR 13276: Argamassa para assentamento e revestimento de paredes e tetos - Preparo da mistura e determinação do índice de consistência. Rio de Janeiro, 2016.

BANTHIA, N.; GUPTA, R. Plastic shrinkage cracking in cementitious repairs and overlays. Materials and Structures, V. 42, 2009.

BAUER, L. A. F.; NORONHA, M. A. A.; BAUER, R. J. F. Uso de aditivos no concreto. In: BAUER, L. A. F. Materiais de Construção. 5. ed. [S.1.]: LTC, v. 1, 2014. Cap. 6, p. 488.

DUVAL, R.; KADRI, E. Influence of Silica Fume on the Workability and the Compressive Strength of HighPerformance Concretes. Cement and Concrete Research, 28, n. 4, 1998. 533-547.

FARIA, E. F. D. Concretos Autoadensáveis de Alto Desempenho com Catalisador Residual do Craqueamento Catalítico Fluído (ECAT) de Refinarias de Petróleo. Tese (Doutorado em Ciências em Engenharia Civil). Rio de Janeiro: UFRJ/COPPE, 2012.

HOLT, E. E. Early age autogenous shrinkage of concrete. Technical Research Centre of Finland, Espoo, v. 446, p. $184,2001$.

KADRI, E. H. et al. Combined effect of chemical nature and fineness of mineral powders on Portland cement hydration. Materials and Structures, v. 43, p. 665-673, 2010.

MEHTA, P. K.; MONTEIRO, P. J. M. Concreto: Microestrutura, Propriedades e Materiais. 3. ed. São Paulo: IBRACON, 2008.

NEVILLE, A. M. Propriedades do Concreto. 5. ed. [S.1.]: Bookman, 2015.

PONS, G.; TORRENTI, J. M. Retração e Fluência. In: OLLIVIER, J.-P.; VICHOT, A. Durabilidade do Concreto: Bases científicas para a formulação de concretos duráveis de acordo com o ambiente. 1. ed. São Paulo: IBRACON, 2014. Cap. 5, p. 139-180.

QIN, R. et al. Effect of shrinkage reducing admixture on new-to-old concrete interface. Composites Part B, v. 167, p. 346-355, 2019.

Y1LD1R1M, G.; SAHMARAN, M.; ANIL, Ö. Engineered cementitious composites-based concrete. In: PACHECOTORGAL, F., et al. Eco-efficient Repair and Rehabilitation of Concrete Infrastructures. [S.1.]: Woodhead Publishing, 2018. p. 387-425. 